war by the merchant seaman, the British Red Cross Society and the Society of St. John together gave to the Seamen's Hospital Society the sum of $100,000 l$. for the purchase of the large building in Endsleigh Gardens which had been used in war-time as an officers' hospital, and for its endowment as a hospital in the first instance for sailors and soldiers who had contracted tropical diseases on service, and ultimately for the sailors in perpetuity. Room in this new Hospital for Tropical Diseases being available, the society decided that the kindred school should be included in the project. This decision was applauded by the school's sponsors at the Colonial Office, and by the stimulating influence of Lord Milner it attracted the necessary financial cooperation of a liberal and appreciative section of the public. Early in the year 1920, therefore, the school was translated from the remote, uncouth neighbourhood of the docks to an accessible London quarter strong in academic associations.

Re-established under such favourable auspices in a central position, the school now prosecutes its original design in all its fullness with an ampler staff and equipment. The well-avouched scheme of a main laboratory course, supplemented by clinical demonstrations and a system of lectures, is unchanged, as it both meets the wants of the man who already has some knowledge of tropical conditions and inspires the man to whom tropical responsibilities are prospective. The clinical instruction, moreover, which appeals so strongly to the practitioner coming home for a season for professional rejuvenation, is improved by the institution of a special clinical laboratory attached directly to the hospital and administered by its staff.
It is, however, to the advanced student-to the inquirer whose interests are not entirely engrossed in medical practice and who appreciates the unlimited opportunities for research that the tropics affordthat the recent developments of the school are more particularly adapted. The departments of protozoology, medical entomology, and helminthology have been reconstituted as distinct units, leaving the original nucleus of tropical pathology as a fourth independent unit. Each unit has its own director, assistant, and subordinate staff, and is equipped to accommodate the individual student who contemplates pursuing some special line of study abroad, or desires to work out particular material collected abroad, or has some set object of his own outside any participation in the general laboratory course in which all the departments co-operate as before. By this arrangement, which also permits a director or an assistant alternatively to go abroad without disturbance of the home routine, research in tropical medicine is doubly seconded. The advanced or special student will also benefit by the proximity of the Tropical Diseases Bureau, which is now housed with the school, and is about to permit a considerable part of its books and serials to be incorporated, as a permanent loan, in a common library.

The changes thus briefly outlined, however, illustrate that inexorable concatenation of pain with pleasure which supplied one of the texts of Socrates' valedictory discourse; for much as the school has gained by its removal, it has lost--for the present, whatever recompense may lie in the womb of Timethe mess and all the concurrent social amenities which graced its old home in the wilderness.

\title{
New Experiments on the Inheritance of Somatogenic Modifications.
}

\section{By Prof. Arthur Dendy, F.R.S.}

$\mathrm{I}^{\mathrm{T}}$ has long been suspected that the problem of the transmission from parent to offspring of somatogenic modifications ("acquired characters") might be solved more readily by physiological experiments directly involving the complex metabolism of the body than by crude surgical operations such as the amputation of limbs. This suspicion has been justified in a remarkable manner by the work of Messrs. M. F. Guyer and E. A. Smith, recently published in the Journal of Experimental Zoology under the general title "Studies on Cytolysins." The physiologists, through their brilliant investigations of serum reactions, have placed a whole armoury of new weapons in the hands of the zoologist, and have even furnished him with a chemical means of determining the degree of relationship, and consequently the correct systematic position, of different "species" of animals. We now have to thank them for giving us a new means of approach to what is perhaps the most difficult problem in biological science.

It has been known for some time that the injection of foreign proteids into the blood of a vertebrate animal calls forth a most profound physiological response, and Messrs. Guver and Smith have taken full advantage of this knowledge in devising their experiments. Bordet showed a quarter of a century ago that when the red corpuscles of the rabbit are repeatedly iniected into the blood of the guinea-pig the latter acquires the power of destroying them, and serum prepared from these "sensitised" guinea-pigs

1 "Some Prenatal "ffects of Lens Antibndie:" (Journ. Exp. Zool., vol. xxvi., May, '918): "Trancmission of Induced Eye Defects" (op. cit., vol, xxxi., August, rozo). NO. 2675 , VOL. IO6] will rapidly dissolve the red corpuscles of the rabbit in vitro, while the serum of untreated guinea-pigs has little or no effect. This experiment formed the commencement of our knowledge of a whole class of substances known as "cytolysins,", which appear in the blood as the appropriate "antibodies" in response to the injection of such substances as red corpuscles, leucocytes, nervous tissue, spermatozoa, and crystalline lens, all of which, "when injected into the blood of an unrelated species, will form lytic substances more or less specific for the antigen used in the sensitising process," the antigens being presumably the characteristic proteids of the substances injected.

The "antibody" or "antitoxin" may be produced in large excess of the amount actually required to destroy the injected foreign proteid, and a highly sensitised serum may thus be obtained. It was with such a serum, sensitised to the crystalline lens of the rabbit, that Messrs. Guyer and Smith conducted their experiments. The serum was prepared by grinding up rabbits' lenses with normal salt solution and injecting the fluid into fowls. A "lens-sensitised" serum was thus obtained, i.e. a serum which would dissolve the lens-substance of the rabbit.

When this lens-sensitised serum is injected into the veins of a pregnant rabbit the youns exhibit a tendency to develop defective eyes-especially as regards the lens, which may be more or less opaque or liauefied. The eyes of the parent are not affected, possibly because in the adult eve the blood-supply to the lens is so meagre that the sensitised serum cannot reach it, or the adult lens may be too tough to be affected by minute quantities of the lysin. The lens of the developing embryo, however, is a very 
delicate structure with an abundant blood-supply, and no doubt the lysin reaches it through the maternal and fotal circulation.

So far, of course, there is no question of any transmission of somatogenic modifications, or "inheritance of acquired characters." The authors have shown, however, that when the young rabbits with defective eyes in their turn produce offspring the defect is inherited. Moreover, it does not gradually diminish and finally disappear in succeeding generations, like the curious somatogenic modification of the shell investigated by Agar in Simocephalus, but actually tends to increase from generation to generation, until the whole eye may almost disappear. The transmission has now been observed through six generations, and-what is still more important as showing that we are dealing with a true case of the "inheritance of acquired characters" - the defect may be transmitted through the male parent only, thus precluding the possibility that it may be due to the action of the maternal blood upon the offspring in utero.

How the germ-cells are affected by the lens lysin is, of course, entirely unknown, and Messrs. Guyer and Smith are commendably cautious with regard to theoretical considerations. It would seem, however, that we have here as clear-cut a case of the inheritance of somatogenic characters as we are ever likely to obtain, and one which may be expected to throw much light on the problem of heredity in general.

\section{The Planet Mars.}

MR. G. H. HAMILTON (Lowell Observatory I Bulletin, No. 82) gives a detailed account, with many drawings, of his observations of the planet Mars at Flagstaff during the apparition of 1918. His observations closely corroborate those of Lowell. He notes that the dark band round the polar cap appears only when the cap is melting; when it is forming, its edges are indistinct. This difference is opposed to the merely optical character of the dark band upheld by some authorities. He also saw a large lake travelling away from the polar cap until it joined the Lucus Hyperboreas. It behaved like surface-water resulting from the melting cap. Mr. Hamilton also claims to have seen the same seasonal development of the canals, proceeding equatorwards, that Lowell described. He notes that the seeing depends on the Martian atmosphere as well as on our own; the details were sometimes blurred and dim, with excellent local seeing.

Conferenze e Prolusioni for December last contains a lecture on Mars by Prof. Pio L. Emanuelli, of the Vatican Observatory. Prof. Emanuelli denies the existence of the geometrical canals, pinning his faith to the results of the largest telescopes. He quotes an interesting observation by Prof. Hale made with the $60-i n$. reflector at Mount Wilson in I909. The seeing was very good, permitting the use of a power of 800 ; the structure of the surface appeared exceedingly complex, far more so than could be shown in a sketch; the dark areas were covered with fine details, not, however, arranged in geometrical patterns. The two canals from the Sinus Sabæus were seen as broad stripes, resolved into minute detail like interrupted and twisted filaments. Prof. Emanuelli quotes similar results from the Yerkes Observatory, and those made in 1909 by $M$. Antoniadi with the 30 -in. refractor at Meudon. He makes, however, no allusion to the necessity of prolonged observation, at various seasons of the Martian year, required to gain an insight into the nature of the processes going on on the planet's surface.

The Journal of the Astronomical Society of India (vol. x., Nos. 7, 8, and 9) contains an article on Mars by Dr. D. N. Mallik, who confines himself, however, to the single question of the Martian origin of the stray wireless signals, concerning which there was considerable discussion in the daily Press last year. Dr. Mallik has no difficulty in establishing the utter improbability of such an origin, though he inclines to the view that animal and vegetable evolution on the two planets would proceed on similar lines, so that if higher forms of life are present on Mars they would be comparable with those on the earth. He is less convincing on the subject of the hopelessness of arranging mutually intelligible signals, assuming: the simultaneous desire to communicate and the conquest of the mechanical difficulties. There is little doubt that under these conditions the united intelligence of the two planets would at least make some progress in communication. The problem recalls the decipherment of cuneiform, being easier in some respects and more difficult in others.

\section{Land Reclamation.}

A TTEMPTS are being made to reclaim some of $A$ the many waste acres in the British Isles, and the problems of reclamation are fully discussed in the Igrg volume of the Journal of the Royal Agricultural Society of England. The general problem is dealt with by Mr. W. Gavin. There is no definite information available as to the extent of either the total uncultivated land or the uncultivated land likely to be capable of cultivation in this country, but Sir Daniel Hall in his report to the Reconstruction Committee tentatively suggested 250,000 acres as the probable area reclaimable for agricultural purposes. Land reclamation has been going on more or less continuously since the beginning of agriculture, and in a closely settled country like England the greater part of the land showing prospects of immediate profitable cultivation has been reclaimed. Therefore, to reclaim the remaining waste land generally requires an expenditure in excess of the immediate value of the land when reNO. 2675 , VOL. IO6] claimed. In some few districts there is land which would pay to reclaim, and in many cases private owners could do the work more cheaply than could the State. On the other hand, such reclamation adds to the national wealth more than the actual value of the land, so that the State can afford to spend more than a private owner. Further, in times of industrial depression it may be of social advantage to the State to provide employment by starting some reclamation schemes.

At a time such as this, when maximum home production is of vital importance to the well-being of the country, Mr. Gavin appeals to all landowners and occupiers to endeavour by some means to increase their cultivated-land area, even though it may not yield immediate profits. It must be remembered that some years must elapse before the full value of any reclamation scheme becomes apparent, though in any case the labour expended is never in vain, since the reclaimed 